\title{
LA GUERRA DE LA NATURALEZA, LA CARESTIA Y LA MUERTE COMO FUENTE DEL DISEÑO DE LOS SERES VIVOS
}

\author{
THE WAR OF NATURE, FAMINE, AND DEATH AS \\ DESIGN SOURCE FOR LIVING BEINGS
}

\author{
Giorgio AIROLDI \& Cristian SABORIDO* \\ UNED
}

\begin{abstract}
Resumen: El proyecto del 'Darwinismo Formal' de Alan Grafen propone una formulación matemática de la teoría de Darwin que pretende demostrar que la selección natural moldea los rasgos fenotípicos a través de la maximización de la eficacia (fitness). El proyecto de Grafen reposa sobre tres premisas: (1) la selección natural es la única fuerza que moldea los fenotipos; (2) la eficacia es la única medida de le evolución; y (3) el diseño biológico surge como resultado de un proceso de optimización selectiva. En este trabajo argumentamos que estas tres premisas limitan la aplicabilidad del modelo a los hechos evolutivos más simples. Esto se debe a que Grafen implícitamente presupone un concepto de eficacia que es a la vez causa y efecto de las novedades fenotípicas; lo que, por un lado, vacía la teoría de Darwin de poder explicativo y, por el otro, lleva a ignorar la potencial contribución de fuerzas evolutivas no selectivas en la configuración de la complejidad biológica. Para superar estos escollos del proyecto de del Darwinismo Formal - que son además comunes a todos los modelos formales adaptacionistas - proponemos sustituir el concepto causal de eficacia por el de robustez, definiendo así el diseño biológico como forma y función en lugar de como maximización de la eficacia.
\end{abstract}

\footnotetext{
* Los autores agradecen sus comentarios a un revisor anónimo de Éndoxa. Este artículo se ha realizado en el marco del proyecto de investigación «MECABIOSOC. Mecanismos en las ciencias: de lo biológico a lo social (FFI2017-89639-P)»

Giogio Airoldi, Departamento de Lógica, Historia y Filosofía de la Ciencia, UNED, Spain. Email: gairoldi1@icloud.com Cristian Saborido, Departamento de Lógica, Historia y Filosofía de la Ciencia, UNED, Spain, EMail: cristian.saborido@fsof.uned.es
} 
Palabras clave: Filosofía de la Biología, Grafen, Evolución, Selección, Diseño Biológico.

Aвsтract: Alan Grafen's 'Formal Darwinism project' proposes a mathematical formulation of Darwin's theory that seeks to demonstrate that natural selection shapes phenotypic traits through the maximization of fitness. Grafen's project is based on three premises: (1) natural selection is the only force that shapes phenotypes; (2) fitness is the only measure of evolution; and (3) biological design arises as a result of a process of selective optimization. In this paper, we argue that these three premises limit the applicability of the model to the simplest evolutionary facts. This is because Grafen implicitly presupposes a concept of fitness that is both cause and effect of phenotypic innovations; which, on the one hand, empties Darwin's theory of explanatory power and, on the other hand, leads to overlooking the potential contribution of non-selective evolutionary forces in the shaping of biological complexity. To overcome these pitfalls of the Formal Darwinism Project - which are also common to all formal adaptationist models - we propose to replace the causal concept of fitness with the concept of robustness, thus defining biological design as form and function rather than as maximization of fitness.

Keywords: Philosophy of Biology, Grafen, Evolution, Natural Selection, Biological Design

\section{El darwinismo aún no formalizado y el proyecto de Grafe}

La complejidad del diseño de los seres vivos ha provocado desde la antigüedad la pregunta por su origen. Frente a las respuestas clásicas de raíz teológica, la propuesta de Darwin fue revolucionaria por su planteamiento además de por su contenido: el diseño inteligente no es un problema que se deba resolver sino un espejismo que se puede disolver. La teoría de la selección ${ }^{1}$ expulsa a Dios del universo biológico, al igual que Laplace, cien años antes, lo había expulsado del universo físico apartándolo como 'hipótesis superflua': la variedad y la complejidad de los organismos no provienen de un acto inteligente de creación, sino 'de la guerra de la naturaleza, de la carestía y de la muerte' (Darwin 1872: 554, traducción de los autores TdA). Dos ideas se derivan de esta concepción: por un lado, que la selección explica la evolución y diferenciación de los rasgos de los organismos; por el otro, que, gracias a la selección y a la acumulación de mejoras

\footnotetext{
1 En todo este artículo, el término 'selección' es sinónimo de 'selección natural'.
} 
incrementales, se conforman de manera gradual y acumulativa los organismos complejos aparentemente 'diseńados' (Birch 2014). Estas dos ideas han tenido destinos muy diferentes. Los modelos de genética de poblaciones formalizan la primera, centrándose en el mecanismo de la evolución, identificado en los cambios de las frecuencias de los alelos en una población. Al estudiar la fuente de la variación fenotípica pero no los rasgos fenotípicos en sí, estos modelos no consideran el diseño de los rasgos ni su relación con las funciones, y rechazan en general que la selección conlleve la maximización de la eficacia. La segunda idea se encuentra en la base de los argumentos adaptacionistas que, al centrarse en el resultado de la evolución, analizan cómo los rasgos fenotípicos contribuyen a la eficacia (fitness) de los organismos, y los explican a través de la maximización de ésta; sin embargo, estos argumentos se quedan al nivel de narraciones informales y obvian los detalles genéticos, considerados irrelevantes para la comprensión de la adaptación desde este enfoque.

En esta situación 'bicéfala', Alan Grafen identifica dos problemas: la falta de formalización de los argumentos del diseño y la carencia de alineación entre las afirmaciones de éstos y los resultados de los modelos de genética de poblaciones. Su proyecto del 'Darwinismo Formal' (Grafen 2014a) se propone dar respuesta a ambos problemas: por un lado, este proyecto sugiere, a través de programas de optimización, una formalización matemática para las explicaciones adaptacionistas; y, por otro lado, muestra que los resultados de la optimización son necesariamente coherentes con aquellos de los modelos de genética de poblaciones. De esta forma, Grafen sostiene que queda demostrado que la selección optimiza los rasgos fenotípicos modificando las frecuencias génicas y los configura en estructuras complejas. En definitiva, Grafen afirma que Darwin tenía razón al defender que la 'lucha por la vida' es la fuente no solo de la variedad, sino también de la complejidad del mundo biológico. En el apartado $\$ 2$ presentamos las líneas generales de la propuesta de Grafen.

En el apartado $\$ 3$ defendemos que las conclusiones de Grafen son cuestionables, ya que se basan en tres premisas que, una vez explicitadas, se revelan problemáticas. La primera es que la selección natural es la única fuerza capaz de moldear los fenotipos, mientras que otras fuerzas y otros procesos no tienen importancia, lo que limita el campo de su aplicabilidad del modelo a los fenómenos evolutivos más simples. La segunda es que la evolución de los fenotipos está dirigida hacia la maximización de la eficacia de los rasgos que la incrementan, lo que transforma la teoría de Darwin en un truismo. La última es que el diseño 
de los organismos consiste únicamente en este proceso de optimización, lo que resulta en una definición muy pobre del diseño y complejidad biológica.

En el apartado $\$ 4$ sugerimos una posible revisión de los intentos de formalización de las narrativas adaptacionistas que supere estas limitaciones. Esta revisión se basa en la inclusión en los modelos formales de una segunda variable para medir los cambios evolutivos: la robustez fenotípica. Después de definir este concepto, ilustramos qué mecanismos pueden incrementar la robustez de un organismo y sugerimos que utilizar esta noción en lugar del concepto de eficacia causal puede solucionar los problemas subrayados en el apartado anterior.

En el apartado $\$ 5$ exponemos las principales ideas principales del artículo y mostramos los posibles desarrollos futuros de la aplicación del concepto de robustez.

\section{EI Proyecto del Darwinismo Formal de Grafen}

Todos los modelos de Genética de Poblaciones se pueden describir en términos del 'teorema fundamental de la selección natural' de Fisher (Gardner 2008, Luque 2017), que vincula las variaciones de eficacia media entre generaciones con la varianza en eficacia de la población inicial, afirmando que "la tasa de crecimiento de eficacia de cualquier organismo en cualquier momento es igual a su varianza genética en eficacia en ese momento" (Fisher 1930: 37, TdA). La sencillez de este principio llevó a Fisher a compararlo con la segunda ley de la termodinámica, según la cual la entropía de un sistema aislado no decrece nunca. Este paralelismo evidencia la consecuencia más controvertida de la propuesta de Fisher: si el teorema está en lo cierto, entonces la eficacia, al igual que la entropía, no debería decrecer nunca, lo que parece estar en clara contradicción con la evidencia empírica. Price (1972), con una formulación puramente matemática, aclaró en qué sentido esto es cierto: la eficacia no decrece, como prevé la ecuación de Fisher, únicamente en aquellos casos en los que la selección es la única fuerza que actúa sobre la población (al igual que la entropía no decrece si el sistema que se analiza está aislado). Si actúan también otras fuerzas, como mutaciones o deriva genética, la ecuación se completa con un segundo término que puede ser negativo y la eficacia global puede así disminuir, tal y como ocurre en la realidad (véase fig.1). 


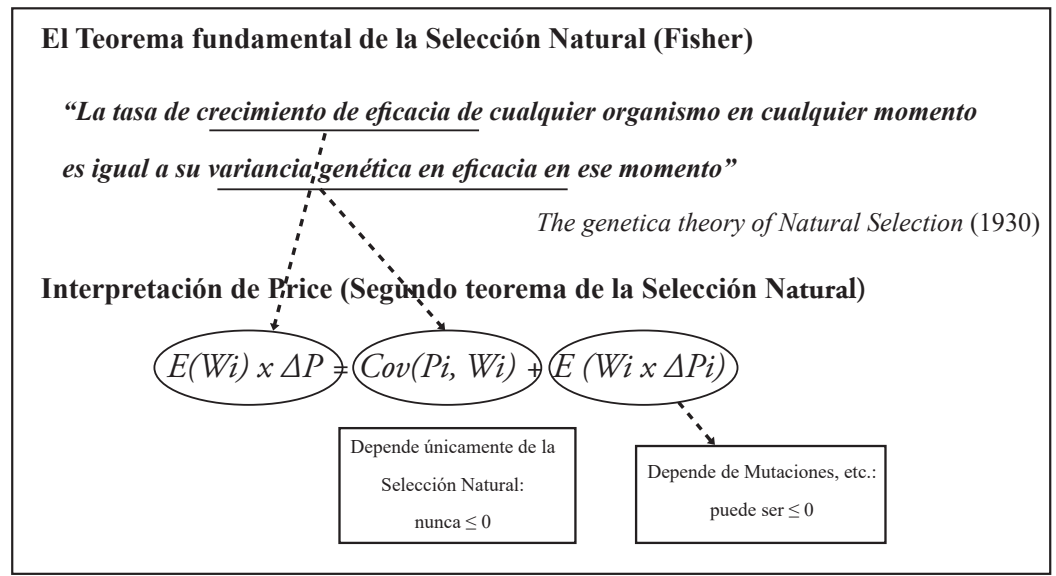

Fig. 1. La ecuación de Price (E es la media; Cov la covarianza; Wi es la eficacia del individuo i; Pi es la frecuencia génica del rasgo i).

En opinión de Grafen, la ecuación de Price resume virtudes y limitaciones de todo modelo de genética de poblaciones: identifica el concepto de eficacia como 'objeto' de la evolución y aísla el motor adaptativo de la evolución (los cambios en las frecuencias génicas dependientes de la selección que incrementan la eficacia) de las influencias casuales que la pueden reducir (mutaciones, deriva, etc). Sin embargo, no postula necesariamente la optimización de la eficacia, sino que considera valores medios y no individuales de las variables y, sobre todo, se centra en el genotipo y no en el fenotipo, que es donde se encuentra el diseño (Grafen 2002: 77). El fenotipo se considera por tanto una 'caja negra' que transforma frecuencias génicas en eficacias medias según mecanismos no analizados directamente por los genetistas poblacionales, en cuanto se considera que no añaden más información a la proporcionada por las frecuencias génicas.

Los argumentos adaptacionistas presentan virtudes y limitaciones en gran parte especulares a las de los modelos de Genéticas de Poblaciones. Estos enfoques explican los rasgos orgánicos en términos de cómo éstos ayudan el organismo a encajar de forma óptima con el entorno, encaje que resulta en la maximización de la eficacia. Se centran así en la explicación del diseño del organismo, interpretándolo como combinación de rasgos, pero consideran secundarios los detalles de la codificación genética de esos rasgos. Es interesante notar como ambas visiones, la de la genética de poblaciones y la del programa adaptacionista, obvian una de las dimensiones de la relación genotipo-fenotipo en base a justificaciones opuestas: la visión poblacional cree que el fenotipo es una consecuencia 
determinista del genotipo, y no puede añadir información relevante para la comprensión de los mecanismos evolutivos, y la visión adaptacionista argumenta que es en el fenotipo en donde actúan esos mecanismos y que, puesto que un mismo rasgo puede fundamentarse sobre diferentes bases genéticas, la información más relevante está más allá de las posibilidades del estudio del genotipo (fig. 2).

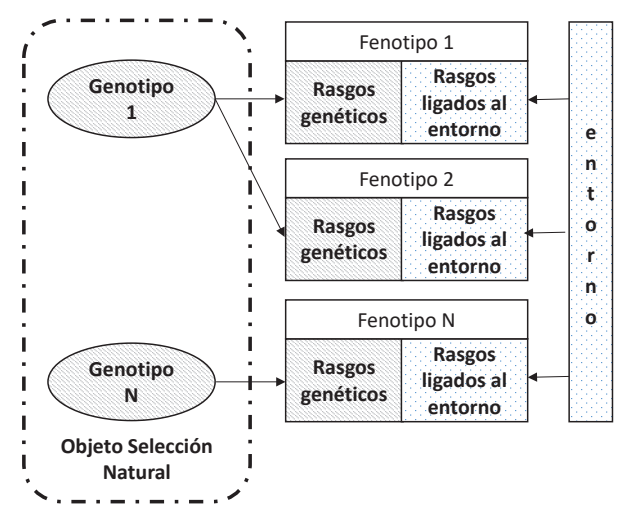

Enfoque Genética de Poblaciones

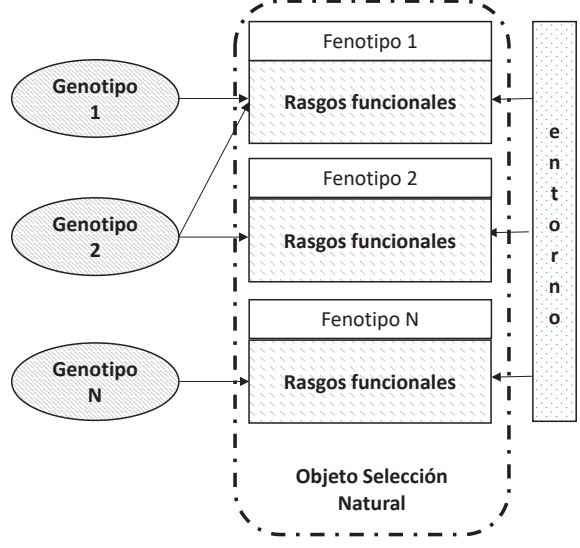

Enfoque del dlseño

Fig. 2. Objeto de la selección para la genética de poblaciones y para el adaptacionismo. La genética de poblaciones considera que los rasgos fenotípicos heredables están completamente determinados genéticamente; los rasgos ligados al entorno (por ejemplo, a fenómenos ligados al desarrollo) no tendrían importancia evolutiva: la selección actúa en consecuencia únicamente sobre el genotipo. El enfoque adaptacionista, por otro lado, considera que los detalles genéticos no son fundamentales para entender la evolución de las funciones fenotípicas ligadas a los rasgos: la presión selectiva empuja a que una determinada función aparezca a partir de una configuración genética u otra.

Los argumentos adaptacionistas carecen en general de modelos formales: su naturaleza narrativa es blanco fácil de críticas y acusaciones de infalsabilidad (por ejemplo, Gould \& Lewontin 1979). Para superar este escollo y poderlos incluir en su proyecto, Grafen aplica a los informales argumentos adaptacionistas el formalismo de los programas de optimización. Su punto de partida es la consideración de los organismos como "soluciones a problemas" (Grafen 2002: 86). Muy comunes en matemática, informática y economía, los programas de optimización modelizan un sistema identificando un decisor que escoge el valor de una variable (el instrumento) dentro de un conjunto de valores admisibles, para optimizar el valor de una función (maximand). El maximand puede ser, por ejemplo, el retorno de una inversión financiera, función del instrumento 'porcentaje de inversión en renta fija y variable'. Los programas de optimización 
no son algo del todo nuevo en biología. Por ejemplo, en los modelos de la teoría del forrajeo óptimo (fig. 3), el instrumento mide el tiempo medio de pasto antes de que el individuo se desplace a otro lugar, y su valor se deduce de consideraciones alrededor de la maximización de la asunción de energía por unidad de tiempo (Charnov 1976).

(I)

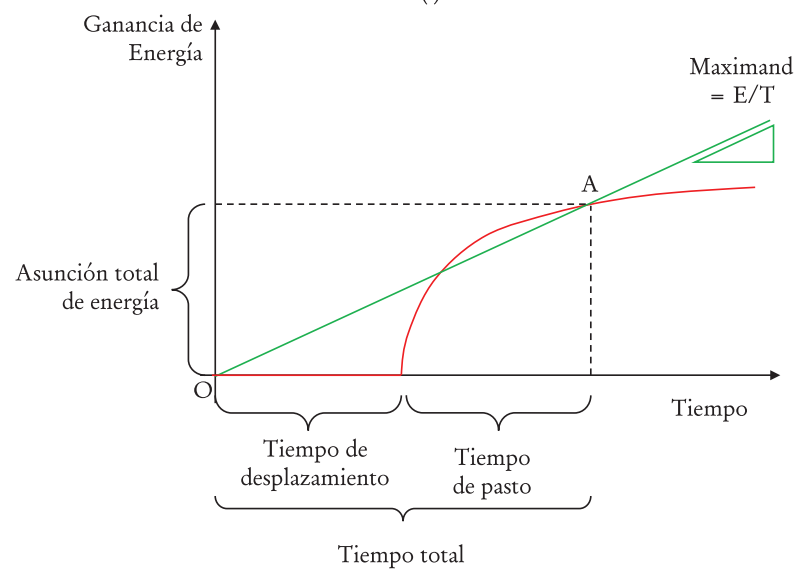

(II)

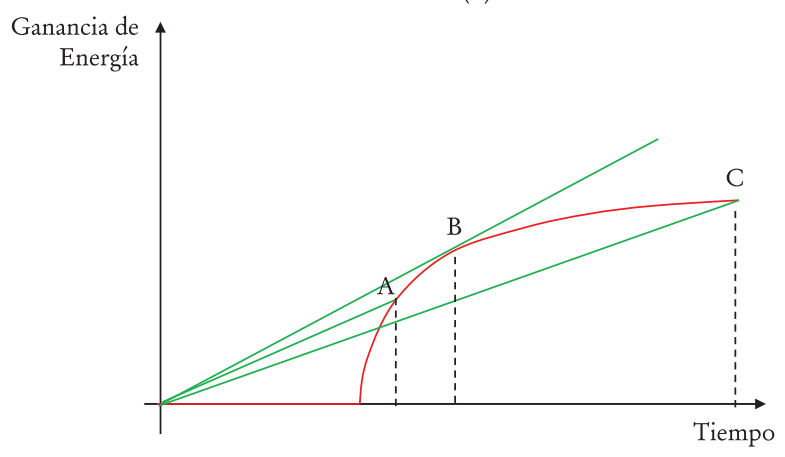

Fig. 3. Programa de optimización para el forrajeo óptimo. (I) ilustra la función que liga la asunción de energía al tiempo total dedicado al forrajeo. El tiempo de desplazamiento para el forrajeo de un lugar a otro conlleva una nula asunción de energía, mientras que la asunción de energía una vez llegado al lugar de pasto sigue una curva de marginalidad decreciente, ya que cuanto más tiempo se forrajea en el mismo lugar, menos comida está disponible y más tiempo hay que dedicar a encontrarla. La ganancia media de energía por unidad de tiempo se considera el rasgo crucial para incrementar la eficacia reproductiva: es el maximand y equivale a la inclinación de la línea que une el punto $\mathrm{A}$ de la función con el centro $\mathrm{O}$ de las coordenadas. El tiempo total dedicado al forrajeo 
es la variable fenotípica a elegir para maximizar el maximand. (II) ilustra los casos en los que el individuo no maximiza la función porqué se va del lugar demasiado pronto (en A) o demasiado tarde (en C); y el caso en el que sí la maximiza (en B), cuando la línea es a la vez tangente de la curva. El modelo prevé que el tiempo correspondiente al punto $\mathrm{B}$ será el valor que se mida en la población real.

Grafen define esta formalización 'matemática de la optimización' contraponiéndola a la 'matemática del movimiento' de los modelos genéticos. Esta terminología se justifica porque los modelos de genética de poblaciones dan cuenta de la dinámica de la evolución entre generaciones sin sugerir que esta apunte a ningún equilibrio. Los programas de optimización se centran por otro lado en la explicación de un estado de equilibrio, sin explicar cómo se ha llegado a ello.

En este contexto, el programa del 'Darwinismo Formal' de Grafen (1999, 2002, 2007, 2014a, 2014b) consiste en el intento de unificar en un único modelo el enfoque genético y el adaptacionista: esta unificación representaría la demostración formal de la idea darwiniana de que la selección explica la complejidad de los organismos. Grafen sostiene que las reglas dinámicas de los modelos de genética de poblaciones conducen necesariamente al estado de equilibrio descrito por el programa de optimización y que, viceversa, este estado de equilibrio es alcanzado necesariamente a través de un camino descrito por los modelos genéticos. Así, podemos establecer un paralelismo con las reglas semánticas y sintácticas de un sistema axiomático: las primeras, como el programa de optimización, nos dicen qué estados son significativos; las segundas, como las ecuaciones de genética poblacionales, nos señalan qué deducciones son admitidas. Las deducciones admitidas llevan necesariamente a estados admisibles y los estados admisibles son alcanzables a través de una serie finita de deducciones correctas.

Para llevar a cabo su proyecto de formalización, Grafen:

1. Construye un modelo de evolución de una población basado en el enfoque genético, aplicando la ecuación de Price.

2. Crea otro modelo de evolución individual basado en el enfoque del diseño, utilizando un programa de optimización. 
3. Finalmente, demuestra que cada uno de estos modelos se puede interpretar y traducir en términos del otro. En condiciones de equilibrio ambos dan los mismos resultados.

La traducción se concreta mostrando que existen unos vínculos necesarios entre los resultados de los dos modelos.

De esta forma, Grafen construye su modelo sobre unas hipótesis que atribuye al argumento original de Darwin:

$\sqrt{ }$ La selección maximiza la eficacia, entendiéndola aquí como eficacia individual y no, como en los modelos de genética de poblaciones, como eficacia media ${ }^{2}$ (Grafen 2002: 86);

$\sqrt{ }$ No es necesario conocer los detalles de la codificación genética de un rasgo fenotípico para entender sus funciones: esta codificación es conocida en muy pocos caso, y sin embargo es posible entender la función de un rasgo (Grafen se refiere a esta hipótesis como 'phenotypic gambit') (Grafen 2002:77). Es obvio que Darwin nada podía saber de genética, pero este desacoplamiento entre gen y función/rasgo se justifica también porque:

a. las funciones se configuran por procesos de maximización de eficacia y no por codificación genética;

b. la misma función puede basarse en configuraciones genéticas diferentes (por ejemplo, flagelos bacterianos y eucariotas comparten algunas de sus funciones con estructuras moleculares completamente diferentes);

c. el mismo rasgo fenotípico puede tener funciones diferentes (por ejemplo, las aletas de las tortugas marinas sirven tanto para nadar como para cavar en la arena).

2 Grafen (2009) utiliza la eficacia inclusiva, concepto que se debe a Hamilton (Hamilton 1964) y que busca explicar el comportamiento altruista en términos de selección. Aunque la selección maximice la eficacia inclusiva, ésta sigue siendo un rasgo del individuo. La selección cambia el objetivo de la maximización, no el agente. Se pasa de la maximización de la eficacia a la maximización de la eficacia inclusiva, pero siempre por parte del individuo, y no del grupo (Gardner 2014b: 105). 
$\sqrt{ }$ La unidad de selección es el individuo, y no el grupo ni el gen: solo el individuo posee un fenotipo y una eficacia, y es sometido a la acción selectiva (Gardner 2014a: 211-212).

Para su modelo de genética de poblaciones, Grafen utiliza la ecuación de Price ignorando el segundo término, es decir, considerando que no se dan más fuerzas que la selección. Con esta hipótesis, ignora la influencia de elementos del entorno, entendido en sentido amplio, cuyos efectos no contribuyen a la optimización de rasgos y al diseño, como por ejemplo la segregación o el sistema de apareamiento (Grafen 2002: 90). En palabras de Grafen: "Asumimos una transmisión imparcial (unbiased)" (Grafen 2008: 427, TdA). La ecuación se reduce entonces a: $\Delta \mathrm{P}=\operatorname{Cov}(\mathrm{Pi}, \mathrm{Wi} / \mathrm{W})$. Adicionalmente, postula la existencia de dos funciones: una $(\omega)$ que liga la eficacia Wi y el fenotipo fi: $\mathrm{Wi}=\omega(\mathrm{f})$, suponiendo así que ninguna otra variable influye en la eficacia; la otra $(v)$ que liga el fenotipo fi al genotipo Gi: $f i=v(\mathrm{Gi})$, suponiendo que ninguna otra variable (por ejemplo, ambiental) que afecte el fenotipo es relevante (Leheman \& Rousset 2014). Sustituyendo estas funciones a la ecuación de Price, obtenemos el modelo dinámico que Grafen utiliza en su demostración: $n$

$$
\Delta \mathrm{P}=\operatorname{Cov}(\mathrm{Pi}, \omega(v(\mathrm{Gi})) .
$$

La configuración del correspondiente programa de optimización es la siguiente:

- El instrumento es el fenotipo individual fi. El individuo resuelve el problema de optimización si su fenotipo da lugar al valor máximo posible del maximand. El instrumento sería algo así como la "palanca" de la que dispone el individuo para definir su estrategia: puede ser cualquier rasgo (físico o de comportamiento) sobre el cual actúe la selección y que tenga algún impacto sobre el éxito reproductivo. En palabras de Grafen: "[es] cualquier cosa sobre la cual actúe la selección: [...] ratio de sexos en los descendientes, tiempo de pasto, masa corporal [...]" (Grafen 2007: 1244, TdA).

- El conjunto $\Phi$ de todos los posibles valores del fenotipo refleja limitaciones fisiológicas, físicas, psicológicas e informacionales, respondiendo a preguntas como: ¿qué puede hacer un animal?, ¿qué eventos pueden condicionar su comportamiento?, ¿̨cuál puede ser el producto de 
una mutación? Se trata de vínculos que unen forma y función (Grafen 2008: 424).

- El maximand $\mathrm{f}$ mide el nivel de éxito correspondiente a cada elección de instrumento, es decir, de fenotipo (Grafen 2007: 1247). Grafen postula que f sea la misma función:

- Para todos los rasgos: esto es coherente con la elección de la eficacia individual en lugar de las eficacias ligadas a rasgos concretos (Grafen 2002: 80).

- Para todos los individuos (hipótesis que define como 'strategic equivalence'): los individuos se pueden diferenciar únicamente por su fenotipo/genotipo, pero no por la estrategia que siguen en el ‘juego’ de la selección (Grafen 2008: 428).

- El programa de optimización se escribe entonces de esta manera ${ }^{3}$ :

$$
\text { fi: } \max f(f) \text {, donde } f i \in \Phi
$$

Es interesante subrayar algunos aspectos de esta formalización. En primer lugar, el fenotipo es el resultado, y no un elemento, del programa de optimización: esto significa que, en principio, habría un programa diferente para cada individuo. El hecho de que el programa coincida para todos los individuos (gracias a las dos hipótesis anteriores) es así un detalle fundamental, que permite pasar de valores individuales a valores medios. En segundo lugar, el programa de optimización no incluye explícitamente ningún elemento del modelo genético: ni población, ni genes, ni frecuencias. En conclusión, la relación entre el modelo genético y el adaptacionista no es en absoluto obvia: la genética de poblaciones habla de poblaciones y genotipos, mientras que los programas de optimización hablan de individuos y fenotipos. El objetivo del Proyecto del Darwinismo Formal es la construcción de un puente entre los dos enfoques, identificando, a través

\footnotetext{
${ }^{3}$ En versiones sucesivas, Grafen complica su modelo para contemplar elementos como la incertidumbre (Grafen 1999, 2000, 2008), la interacción social (Grafen 2006a) y las clases de individuos (2006b). Los supuestos fundamentales y la mecánica del modelo permanecen sin embargo iguales en todas estas versiones, y por esta razón se ha circunscrito esta discusión a la versión básica del modelo.
} 
de una traducción adecuada, qué elementos del modelo dinámico coinciden con qué elementos del modelo de optimización.

La fig. 4 resume los elementos de los dos modelos y las relaciones estipuladas entre ellos, que permiten la traducción de un modelo al otro:

1. El instrumento del programa de optimización coincide con el fenotipo individual $\phi \mathrm{i}^{4}$.

2. El maximand es la función $\omega$ que liga la eficacia al fenotipo $\phi i$ (Grafen 2007: 247). La función f a maximizar en el programa de optimización coincide con la eficacia en la ecuación de Price:

$$
f=\omega
$$

Se puede establecer esta igualdad gracias a los dos supuestos estipulados por Grafen:

$\sqrt{ }$ es posible asociar a todo individuo el mismo maximand;

$\sqrt{ }$ el razonamiento que se lleva a cabo para un individuo cualquiera $\mathrm{i}$ es así extensible a cualquier otro individuo j, y a la población entera.

En el enfoque de Grafen, la eficacia es una función que, independientemente de las limitaciones propias de cada individuo, comparten todos ellos. El paso de los modelos de genética de poblaciones a los de optimización se basa en esta unicidad: si varios individuos maximizaran funciones diferentes, las vinculaciones de Grafen dejarían de valer. El maximand es así la eficacia: de hecho, según Grafen, está es la única manera de proporcionar una definición formal de la eficacia (Grafen 2008: 424-425).

${ }^{4}$ Esta caracterización supone el fenotipo como dado de forma exógena al modelo mismo, y no como su producto. El modelo de Grafen no captura por tanto la posibilidad de que limitaciones del entorno impidan que el fenotipo óptimo se desarrolle y se fije (Huneman 2014: 276). 
3. Las limitaciones que determinan el conjunto $\Phi$ de posibles valores del instrumento en el modelo de optimización están determinadas y limitadas por la genética.

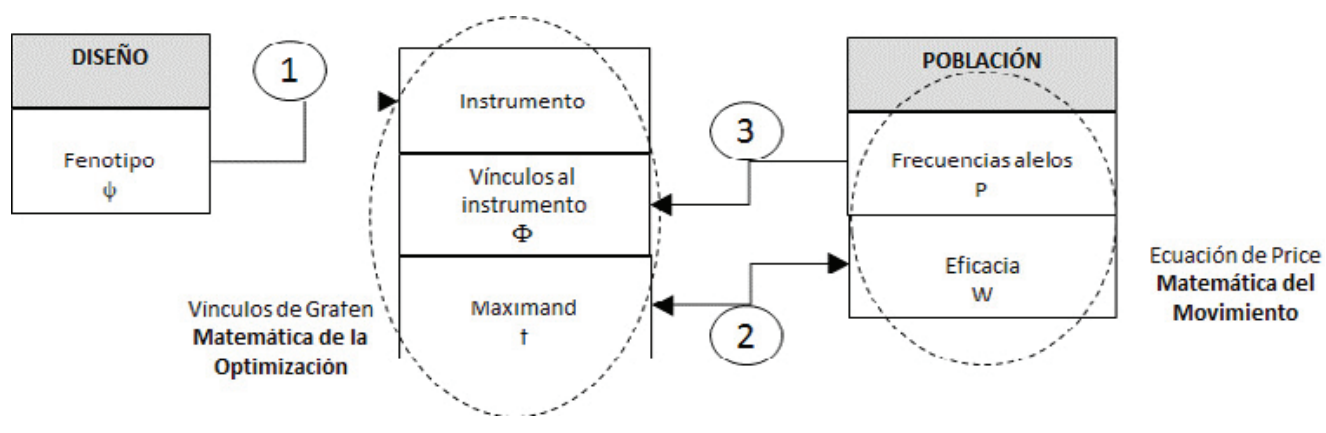

Fig. 4. Elementos del modelo de Grafen

Gracias a esta traducción, Grafen puede analizar cómo los resultados de un modelo se relacionan con los resultados de otro en un estado cualquiera de la población, sea este de equilibrio o no, e identifica cuatro vínculos necesarios que reflejan estas relaciones (Grafen 2002: 87-88):

I Si cada individuo resuelve el programa de optimización (enfoque del diseño), entonces la variación esperada en la frecuencia de los alelos es nula y ningún nuevo fenotipo se extenderá por la población (dinámica genética).

II Si cada individuo llega al mismo valor de la función de optimización pero no resuelve el programa (enfoque del diseño), entonces la variación genética es nula pero podría aparecer un mutante que se extienda por la población (dinámica genética).

III Si cada individuo llega a un valor diferente de la función de optimización (enfoque del diseño), las variaciones en las frecuencias de los alelos equivalen a la covarianza entre gen y eficacia (dinámica genética). Esta es una reformulación del teorema de Fisher y captura la dinámica de la evolución dentro de una población que está evolucionando y cuyos individuos buscan solucionar el programa de optimización. 
IV Si el cambio esperado en la frecuencia de cada gen es nulo, y no existe un posible fenotipo que pueda invadir el grupo (dinámica genética), entonces cada individuo resuelve el problema de optimización (enfoque del diseño). Este vínculo es especular al primero (I).

Los tres primeros vínculos estipulan un estado para el programa de optimización y permiten deducir conclusiones sobre los correspondientes cambios en las frecuencias de los genes. El cuarto vínculo se mueve en dirección contraria, desde los cambios en las frecuencias génicas al estado del programa de optimización: captura la idea de que los mecanismos de herencia y reproducción permiten que el individuo actúe como un decisor racional (nótese que se trata por supuesto de una metáfora y que Grafen no imputa ninguna intencionalidad consciente) (Grafen 2007: 1248).

De esta forma, Grafen consigue demostrar que la fijación de los alelos de acuerdo con la ecuación de Price conlleva automáticamente la maximización de la función de optimización, es decir, de la eficacia del fenotipo. Una vez maximizada la función de optimización en todos los individuos, no se dan variaciones de eficacia en la población: la variación inter-generacional en la ecuación de Price se anula. Existe por lo tanto un isomorfismo entre selección y optimización (Huneman 2014: 274). Los vínculos demuestran que la optimización por selección no es un caso particular, sino una tendencia general.

\section{Las premisas del Proyecto de Grafen}

El proyecto del darwinismo formal toca un aspecto fundamental de la biología actual y no es de extrañar que haya despertado reacciones dispares que van desde la aceptación entusiasta al rechazo frontal ${ }^{5}$. En esta sección, exponemos los que consideramos las tres premisas principales implícitas del modelo, y que creemos limitan el alcance de la propuesta de Grafen:

A. La selección es la única fuerza capaz de actuar de manera constante y estructurada para moldear la forma de los organismos: la contribución de otras fuerzas y mecanismos es o bien insustancial o fortuita, ya que no afectan de forma consistente la eficacia;

\footnotetext{
5 Véase por ejemplo Biology and Philosophy Volume 29, issue 2, March 2014: 155-270.
} 
B. El impacto de la selección sobre los rasgos se rige por la optimización de la eficacia (fitness) individual;

C. La optimización de la eficacia individual lleva al surgimiento del diseño.

Las tres premisas, como vemos, se basan en el concepto de eficacia, que representa el pilar básico de todo el modelo. En esta apartado, ilustramos y criticamos las premisas y el rol de la eficacia en cada una de ellas.

\section{(A) El rol de la selección natural}

Grafen otorga a la selección un papel fundamental en el surgimiento del diseño. Esta afirmación se declina en una doble vertiente: por un lado, la selección optimiza el diseño entre todos los actualmente disponibles; por el otro, puede generar diseños novedosos sin limitaciones. En este apartado, analizamos las dos afirmaciones por separado, y mostramos cómo reduzcan el alcance explicativo del modelo.

La selección como fuerza optimizadora de los rasgos existentes. Con respecto a la primera vertiente, la selección es vista como la única fuerza capaz de empujar de forma consistente hacia la optimización. Otras fuerzas evolutivas (por ejemplo, la deriva genética) se consideran como secundarias, puesto que su acción es demasiado casual para poder ser capturada por un modelo formal. Por esta razón, de la ecuación de Price se elimina el elemento ligado a la transmisión que da cuenta de las variaciones de frecuencias génicas por mutaciones y demás cambios en el entorno físico, biológico y cultural. Con esta simplificación, Grafen no niega estos fenómenos, únicamente afirma que no tienen un impacto consistente e inevitable en el surgimiento del diseño. Sin embargo, si otras fuerzas evolutivas, aunque no tan sistemáticas como la selección, juegan también un papel importante, entonces estas se deberían incluir en el modelo, sin importar la dificultad de formalización que eso conlleve. Además de esta dimensión epistemológica del problema, hay también una empírica. Se debería medir (y definir además cómo entendemos 'medir' en este caso) la importancia relativa de todas ellas. Es muy posible que el impacto de la selección sea más fácil de medir porque es más fácil de formalizar, pero en este caso no debería contrastarse con un juicio informal alrededor de otras fuerzas. Orzack (2014) considera que la primacía de la selección sobre otras fuerzas evolutivas se debería demostrar, por 
ejemplo, comparando los resultados de un modelo que las incluya y de uno que no. También Ewans (2014: 202-204) detecta una falta de fundamento empírico en la teoría: el modelo por sí solo y sin recurso a datos reales es insuficiente para establecer nada acerca de la naturaleza de aquello que modeliza. Grafen obvia los aspectos problemáticos epistemológicos y empíricos y parece en definitiva postular aquello que debería demostrar: que la selección es la principal fuerza moldeadora del diseño. Sarkar se pregunta cuál es realmente la importancia de la selección para la evolución y a qué nivel ésta actúa, poniendo en duda su rol en la configuración de la arquitectura del genoma (Sarkar 2014: 256). Orzack recuerda que la mayoría de los biólogos, aunque reconozcan la importancia de la selección, no descartan otras fuerzas (Orzack 2014: 264). Las virtudes de la selección como motor de la optimización parecen además acercar a Grafen a una posición adaptacionista extrema: su modelo considera que la selección actúa sobre todos los rasgos del organismo y los lleva hacia una conformación óptima. Contra esta versión extrema del adaptacionismo existen muchas críticas en la literatura. Maturana y Varela (1980) sostienen que quien sobrevive no es únicamente el 'más apto', sino todos los 'suficientemente aptos' y que la selección fija un nivel minimo de adaptación, por encima del cual cohabitan muchas soluciones adaptativas, y no un nivel máximo hacia el cual todos los fenotipos deben moverse o desaparecer. Pigliucci (2008b), subraya que la 'ley de Darwin' no postula la supervivencia del más apto sino más bien la no supervivencia del no suficientemente apto. En conclusión, la hipótesis de Grafen con respecto al rol optimizador de la selección parece explicar los rasgos fenotípico a través de un proceso de optimización únicamente en tiempos de crisis y escasez de recursos y solo con respecto a rasgos relevantes y ya presentes.

La selección como fuerza creadora de nuevos rasgos. Grafen parece además otorgar a la selección la capacidad de generar sin límites nuevos rasgos. La literatura cuenta con muchos argumentos que relativizan esta pretensión. Al igual que la selección artificial modifica los caracteres existentes pero no puede crear caracteres nuevos (existen muchas razas de perros pero ninguno con alas o antenas), la capacidad de la selección natural para generar rasgos ilimitadamente gracias a la acumulación de pequeñas mejoras es dudosa. Se ha sugerido que el surgimiento de rasgos radicalmente novedosos puede ir ligado a mecanismos no selectivos y no incrementales. Ya Wright sostuvo que las causas del movimiento desde un pico adaptativo a otro más alto, cruzando un valle, se deben buscar en mecanismos diferentes de la selección, ya que ésta, en entornos estables, solo permite movimiento hacia eficacias mayores (Fisher 1930). Su teoría shifting-balance (Wright 1982) sugiere que las novedades sobre las cuales actúa la selección brotan, en 
tiempos evolutivamente cortos, de procesos de deriva genética en poblaciones de tamańo mediano y asiladas geográficamente, gracias a fijaciones y pérdidas casuales de alelos que permiten recombinaciones de otras formas imposibles o muy improbables. Puesto que la relación entre alelos y rasgos fenotípicos es compleja y no-aditiva, estas recombinaciones pueden dar lugar a fenotipos novedosos aún sin la contribución sustancial de mutaciones. El mecanismo de 'mutación de impacto pequeño más selección’ no podría explicar las novedades fenotípicas más significativas, porque actúa en tiempos demasiado largos, porque las mutaciones relevantes son en general letales y porque tiende además a destruir la variedad, siendo un proceso que se finaliza a sí mismo: el polimorfismo de muchas especies sería en este sentido el punto final de equilibrio de un proceso selectivo, y no una fuente para futuras adaptaciones. La teoría de los equilibrios puntuados de Gould y Eldredge (Eldredge \& Gould 1972) se basa en la misma idea de que cambios fenotípicos rápidos y limitados a sub-poblaciones marginales se extienden después, si resultan exitosos, al resto de la población. Otra potencial fuente de rasgos novedosos se ha identificado en las exaptaciones, rasgos que adquieren un valor adaptativo sin que se haya llegado a ello a través de un proceso de selección (Gould \& Vrba 1982). La fuente de variabilidad que alimenta la selección se ha identificado además en procesos intrínsecos a los organismos, considerados como sistemas complejos que se auto-organizan (Kauffman 1993, 2000), en las restricciones genéticas y de desarrollo que predeterminarían qué organismos son posibles (Alberch 1991, Houle 1992, Wagner \& Altenberg 1996), en la estructura lógica de las redes genéticas que permiten la exploración del espacio fenotípico (Wagner 2011, 2015), en mecanismos cuasi-lamarckianos tales como las mutaciones no casuales (Jablonka \& Lamb 1998, Koonin \& Wolf 2009), y en mecanismos epigenéticos (Jablonka \& Lamb 2005), por citar solamente algunas de las principales propuestas.

Otorgando en su modelo un papel preponderante a la selección natural en el surgimiento de novedades fenotípicas y en su optimización, Grafen si sitúa en una tradición muy extendida entre los biólogos. Las simplificaciones que introduce, luego, son coherentes con los principios del paradigma adaptacionista al que adhiere, y que su modelo consigue formalizar con éxito. Sin embargo, creemos que estas simplificaciones marcan de forma implícita los límites del espacio lógico de aplicabilidad de su modelo. Para ilustrarlo, recurrimos a la discusión sobre el concepto de 'evolvabilidad' en Pigliucci (2008a), en la cual se sugiere clasificar los diferentes sentidos que en la literatura se dan al concepto de 'evolvabilidad' en base a los niveles de evolución a los que se refieren y a las fuerzas evolutivas que predominan en cada nivel (tabla 1). 
Tabla I. Clasificación de cambios evolutivos (basado en Pigliucci 2008a: 76, table 1)

\begin{tabular}{|c|c|c|c|c|}
\hline \multicolumn{5}{|c|}{ El 'espectro conceptual' de la evolvabilidad } \\
\hline $\begin{array}{l}\text { Término } \\
\text { sugerido }\end{array}$ & $\begin{array}{l}\text { Nivel de } \\
\text { aplicación }\end{array}$ & Descripción & Efectos & Ejemplos \\
\hline Heritabilidad & $\begin{array}{l}\text { Dentro de } \\
\text { una pobla- } \\
\text { ción }\end{array}$ & $\begin{array}{l}\text { Acervo génico } \\
\text { actual (varianza y } \\
\text { covarianza) }\end{array}$ & $\begin{array}{l}\text { Determina la respue- } \\
\text { sta a la selección den- } \\
\text { tro de la población }\end{array}$ & $\begin{array}{l}\text { Cambio de } \\
\text { color en B. } \\
\text { betularia }\end{array}$ \\
\hline Evolvabilidad & $\begin{array}{l}\text { Dentro de } \\
\text { una especia }\end{array}$ & $\begin{array}{l}\text { Incluye la varia- } \\
\text { bilidad, depende } \\
\text { de la arquitectura } \\
\text { genética y de las } \\
\text { restricciones de } \\
\text { desarrollo }\end{array}$ & $\begin{array}{l}\text { Impacta la adaptación } \\
\text { a largo plazo, canaliza } \\
\text { la evolución en trayec- } \\
\text { torias no casuales, } \\
\text { permite la exploración } \\
\text { a medio plazo del } \\
\text { espacio fenotípico }\end{array}$ & $\begin{array}{c}\text { Diferenciación } \\
\text { de los pinzones } \\
\text { de Darwin }\end{array}$ \\
\hline Innovación & $\begin{array}{l}\text { Dentro de } \\
\text { los clados }\end{array}$ & $\begin{array}{l}\text { Como dentro de } \\
\text { una especie, pero } \\
\text { incluye la capa- } \\
\text { cidad de superar } \\
\text { el acervo génico } \\
\text { actual y las restric- } \\
\text { ciones de desarrol- } \\
\text { lo, abriendo nuevas } \\
\text { áreas del espacio } \\
\text { fenotípico para } \\
\text { futuras evoluciones }\end{array}$ & $\begin{array}{l}\text { Genera considerables } \\
\text { avances fenotípic- } \\
\text { os (morfológicos, } \\
\text { comportamentales o } \\
\text { fisiológicos) }\end{array}$ & $\begin{array}{l}\text { Aparición del } \\
\text { caparazón de } \\
\text { las tortugas }\end{array}$ \\
\hline
\end{tabular}

En el nivel más bajo (tanto el de la evolvabilidad como el de la heritabilidad), la evolución consiste en los cambios de frecuencias génicas entre generaciones de una población determinada, cambios que los modelos de genética de poblaciones describen con éxito. Los rasgos se encuentran definidos y su combinación es moldeada por la selección. Está claro que el modelo de Grafen tiene su aplicación más natural en este caso. La evolución del color de las alas de la $B$. betularia proporciona un ejemplo clásico de hecho evolutivo para este nivel: el rasgo y sus posibles variantes están bien definidos y sus frecuencias relativas resultan de un proceso de selección, que premia el color que asegura un mejor mimetismo. Sin embargo, es en los niveles más altos (como el de la innovación), donde aparece un concepto de diseño biológico más refinado, que conlleva modificaciones de los rasgos (como en al caso de los pinzones de Darwin), o nuevos rasgos y 
funciones (como en el caso del caparazón de las tortugas). En estos casos, no parece obvia la aplicación de modelos de optimización, y en particular del modelo de Grafen, ya que sus hipótesis no se cumplen. Por un lado, las variables del modelo varían antes y después del hecho evolutivo: por ejemplo, si la morfología o la función de un rasgo mudan, la función a maximizar también cambia a lo largo del proceso, y el problema pasa a ser no-lineal. Por el otro, como hemos visto, no hay un acuerdo sobre la relevancia relativa de la selección y de mecanismos no selectivos en estos fenómenos.

El modelo de Grafen identifica en la eficacia la única variable relevante para la evolución. Pero la eficacia, en su formulación más simple, mide el efecto de la selección en una población. Otros procesos y leyes no la impactan, puesto que sus efectos no son funciones de la eficacia de los individuos (Lynch 2007). Novedades fenotípicas exitosas, sin embargo, "pueden aparecer sin estar acompañadas por diversificación y pueden darse retrasos entre la aparición de una novedad y su explotación exitosa como innovación” (Erwin 2015: 937, TdA). Esto significa que cambios en el fenotípo pueden aparecer sin que haya un correspondiente efecto en la eficacia (lo que Erwin llama 'diversificación'). La tradición adaptacionista apela a esta falta de efecto en la eficacia para declarar la insignificancia de los procesos no-selectivos en la evolución. El razonamiento adaptacionista es el siguiente: un rasgo se explica gracias a su contribución a la eficacia, luego todo proceso evolutivo debe impactar la eficacia o es irrelevante en cuanto a al evolución del rasgo; pero la eficacia es por definición una medida de selección, luego ningún otro proceso que no sea la selección es causa de los rasgos.

\section{(B) La eficacia como explanans de los rasgos}

El uso de la eficacia individual como variable de optimización en el modelo de Grafen se basa en dos sutiles modificaciones del original concepto darwiniano de 'fit', o encaje entre individuo y entorno. Darwin escribe:

Los descendientes también tendrán pues una mayor probabilidad de sobrevivir, puesto que, de los muchos individuos que nacen periódicamente, solo una pequeña cantidad puede sobrevivir. He llamado a este principio, por el cual cualquier mínima variación, si útil, se mantiene, con el término de selección natural, para subrayar su relación con el poder de selección del hombre. Pero la expresión a menudo utilizada por el señor Spencer de la 
sobrevivencia del más apto [fittest] es más precisa, e igualmente conveniente. (Darwin, Origin 1872: 77, traducción y cursivas de los autores, TCdA).

Como vemos, la eficacia como número escalar y medible no aparece en Darwin: es Fisher quien, sesenta años después, mientras afirma formalizar la teoría de la selección, cambia sutilmente el enfoque. Por un lado, en lugar de individuos habla de genotipos:

[los] genotipos son probablemente adecuados en forma desigual [...] a la tarea de sobrevivir y reproducirse (Fisher 1930: 9-10, TCdA)

Por el otro, en lugar de las propiedad de un individuo de encajar con el entorno, crea un nuevo concepto, tomando prestada la idea de la dinámica de poblaciones Malthusiana (Malthus 2008): la eficacia m de un gen, un valor escalar que resumen todo lo que es relevante para entender el pasado y el futuro evolutivo de un organismo:

Puesto que m mide la eficacia [fitness] para sobrevivir [...] (Ibíd., 33, TCdA)

Este concepto de eficacia (individual o reproductiva, Sober 2009) mide a posteriori el éxito reproductivo de un individuo. Es la eficacia que aparece en los modelos de genética de poblaciones, y de por sí no pretende explicar porqué un rasgo existe, entre otras cosas porque no se refiere a un rasgo si no al fenotipo como unidad indivisible. Es una herramienta predictiva, que mide el éxito de un gen y permite prever la evolución del acervo genético de una generación a la siguiente: no se compromete con la idea de optimización de rasgos (Fisher 1930, Ewans 2012), ni defiende ninguna narrativa alrededor de la sus historias evolutivas. Si un gen proporciona mayor eficacia, proliferará en la población: pero porqué proporciona mayor eficacia no es un tema abordado por los modelos de genética de poblaciones.

La segunda modificación que lleva desde el encaje (fit) de Darwin hasta la eficacia (fitness) de Grafen es el paso a la eficacia ecológica (Sober 2009), o de un rasgo específico, que mide, a través del análisis a-priori de su 'buen diseño', la contribución parcial de éste al éxito reproductivo global del individuo. A nivel informal, se trata del concepto manejado en las narrativas adaptacionistas cuando explican por ejemplo el cuello de la jirafa por su contribución a la sobrevivencia. Puesto que se mide el desempeño futuro esperado del rasgo, la eficacia ecológica 
es un concepto disposicional y, como tal, difícil de medir directamente. Los rasgos no aparecen nunca aislados y la fragmentación de un organismo en rasgos conlleva una gran subjetividad (¿la longitud de un miembro es un rasgo, o lo es la longitud de cada elemento del arto?).

La tabla 2 resume las características de los dos conceptos de eficacia.

TABLA 2. Eficacia ecológica, o de un rasgo y eficacia reproductiva, o individual.

\begin{tabular}{|c|c|c|c|c|}
\cline { 2 - 5 } \multicolumn{1}{c|}{} & Referida a & Enfoque & Performance & Uso \\
\hline Ecológica & Un rasgo & A priori & Esperada, futura & $\begin{array}{c}\text { Argumentos } \\
\text { adaptacionistas }\end{array}$ \\
\hline Reproductiva & El individuo & A posteriori & Medida, pasada & $\begin{array}{c}\text { Genética de } \\
\text { poblaciones }\end{array}$ \\
\hline
\end{tabular}

Con este segundo cambio, el concepto de eficacia se vuelve una herramienta explicativa: pretende explicar porqué un rasgo existe: y la respuesta es que existe porque garantiza mayor eficacia. La eficacia se vuelve de esta forma a la vez la medida y la causa del éxito evolutivo: es decir, causa y efecto de la reproducción diferencial (Rosenberg \& Williams 1986). Algunos autores creen que la interpretación de la eficacia como explanans de la evolución imposibilita su definición de forma independiente de los conceptos de sobrevivencia y reproducción, y que esta imposibilidad transforma la teoría de Darwin en una teoría circular: si el mas eficaz sobrevive (efecto), y el más eficaz es aquel que sobrevive (causa), la teoría simplemente afirma que aquel que sobrevive, sobrevive (Mills \& Beatty 1979). La circularidad se debe a que se utiliza la eficacia a la vez para resumir el éxito de un diseño midiendo sus resultados y para dar cuenta de las causas de este éxito. Kauffman (1993: 17) afirma que la circularidad entre conceptos es una constante inevitable en toda teoría: en la segunda ley de Newton, por ejemplo, fuerza y masa se definen la una en términos de la otra. Otros autores, sin embargo, proponen evitar el truismo recurriendo a un principio externo a la teoría que pueda actuar como causa de los rasgos (principio que existe por ejemplo en la selección artificial, donde es el criador quién decide qué individuos se reproducirán). Sober (2009) distingue entre la eficacia como la habilidad de sobrevivir en un entorno (viability, o de pasar de zigoto a adulto) y la habilidad de reproducirse (reproductive fitness, o de pasar de adulto a zigoto): propuesta que soluciona el problema del truismo, si consideramos que sobrevivir requiere rasgos cuyas causas no están ligadas al hecho de que incrementen la habilidad de reproducción; pero que conserva las limitaciones del concepto de eficacia, 
puesto que ambas versiones de la eficacias miden las dinámicas evolutivas ex post. Aplicando un símil, es como afirmar que el mejor coche es aquel que ha ganado la carrera (viability) o aquel con la tecnología más copiada (viability fitness): aunque ciertas, ninguna de estas afirmaciones ayuda a entender porqué el coche ha ganado, ni porqué su tecnología es tan copiada. Mills y Beatty (1979) interpretan la eficacia-causa ${ }^{6}$ como una propensión reproductiva a tener un número esperado de descendientes. Tal propensión se define analizando los rasgos relevantes en base a consideraciones externas a la teoría de la selección natural (por ejemplo, el análisis de ingeniería de los rasgos). Millstein (2006) sugiere sustituir la eficacia-causa con 'diferencias físicas causalmente relevantes', donde la relevancia se debería definir en términos de consideraciones alrededor de las bases físicas de la adaptación. La dependencia de la definición de eficacia de teorías externas se ha usado para afirmar que se trata de un 'término teórico primitivo', indefinible dentro de la teoría de la selección natural (Rosenberg 1982, Rosenberg \& Williams 1986). A pesar de que estas propuestas, contrariamente a la de Sober, son en efecto ex ante, siguen enfocada en el éxito reproductivo, luego en la fase selectiva de la evolución.

\section{(C) El diseño biológico como proceso de optimación}

El último paso del modelo de Grafen se basa en la idea de que la optimización generada por selección conduce al surgimiento de cualquier diseño. Sin embargo, esta equivalencia no es de mucha ayuda ni para identificar el diseño ni para juzgar si un diseño es mejor que otro. Por ejemplo, el estado físico de un sistema puede ser óptimo sin mostrar mayor diseño que estados sub-óptimos. Si seleccionamos la energía potencial como la función a optimizar, una pelota en el fondo de un hemisferio se encuentra en un estado óptimo, pero no presenta mayor diseño que la misma esfera moviéndose armónicamente arriba y abajo. El óptimo no parece así coincidir, en general, con el diseño. Aun admitiendo que optimización y diseño puedan ser conceptos íntimamente ligados, esta vinculación parece darse de una forma compleja y sutil que necesita de un análisis pormenorizado y no puede darse por sentada ${ }^{7}$. Además, no está claro qué se entiende en el modelo de Grafen por 'mejor diseño'. Recurriendo al ejemplo ya citado anteriormente, el color de las alas de la mariposa Biston betularia puede

\footnotetext{
6 Para evitar confusiones, hablamos de eficacia-causa cuando nos referimos al concepto adaptacionista y eficacia-efecto cuando nos referimos al concepto genético poblacional. Esta terminología no se encuentra en la literatura.

7 Toda esta analogía en (Birch 2014: 177).
} 
cambiar del blanco al negro y viceversa, según cual sea el color más común de la corteza de los árboles donde suelen posarse. Las ecuaciones de Genética de poblaciones prevén con precisión estos cambios, pero no interpretaríamos uno de los dos fenotipos como mejor diseńado que el otro, a pesar de que representa, en cierto sentido, un nuevo óptimo. Finalmente, la presunta optimización de un rasgo puede ser prueba de que la selección ha actuado, pero esto no sirve como demonstración de que si la selección actúa el rasgo se optimiza. Los casos de exaptación muestran como un rasgo surgido para una función puede aprovecharse para otra (Gould \& Vrba 1982). Además, la selección no parte nunca desde cero. Las jirafas ya tenían un cuello con una historia evolutiva aún antes de que este rasgo tuviera su actual estructura y desempeñara su actual función.

Si el diseño no es un simple reflejo de la maximización de la eficacia, ¿`cómo se puede entonces definir? El problema principal del concepto de diseño sea tal vez que carece de una definición única, formal y explícita. Tal y como hemos visto que ocurría con el concepto de eficacia, la naturaleza polisémica del concepto de diseño dificulta circunscribir exactamente de qué está hablando cada autor. Además, sería necesario depurar el concepto de todo elemento psicológico que nos lleve a ver 'diseño' en algunos estímulos y no en otros (Birch 2014).

El problema se remonta a Charles Darwin, quien admite que "[...] los naturalistas no han definido con satisfacción unánime qué se entiende por avance en la organización." (Darwin 1872: 141, TdA). Hoy la situación no ha mejorado: en la literatura se encuentran muchas propuestas para definir el diseño biológico o, dicho en otros términos, la complejidad biológica. En genéticas de poblaciones, ésta se reduce a la complejidad del fenotipo: "[damos por supuesto] que la complejidad de un organismo refleja la complejidad física de su genoma" (Adami and al. 2000: 4463, TdA). Un adaptacionista como Grafen no proporciona una definición formal, pero afirma que "la adaptación es diseño, y los organismos están diseńados para maximizar su eficacia [fitness].” (Grafen 2007: 1248, TdA) y parece así identificar la complejidad biológica como la causa remota del incremento de la eficacia fenotípica, cuya causa próxima es la selección. En definitiva, Grafen parece interpretar el diseño como la mezcla de caracteres que asegura una eficacia óptima (la misma idea es defendida en Gardner 2009): sin embargo esta definición parece fallar en los ejemplos citados anteriormente (la diferenciación en los pinzones de Darwin y la aparición del caparazón en las tortugas).

Fuera del ámbito de la biología, tampoco hay acuerdo sobre una única definición de complejidad. El enfoque de la 'ciencia de la complejidad' identifica la 
complejidad como un fenómeno emergente que surge de la interacción entre elementos homogéneos y relativamente simples, que constituyen sistemas abiertos, non-jerárquicos y lejos del equilibrio, en la frontera entre orden y caos (Kauffman 2000). Para Mitchell (2009), los sistemas complejos como los biológicos muestra comportamientos no triviales, emergentes y auto-organizativos. Para Johnson (2010), un sistema complejo es una sutil mezcla entre orden y desorden, y se mueve entre los dos estados. El enfoque HOT (Highly Optimized Tolerance) de Carlson y Doyle (2002), por otro lado, caracteriza los sistemas complejos como compuestos por elementos heterogéneos organizados en estructuras jerárquicas que constituyen organizaciones robustas contra turbulencias esperadas, pero frágiles contra las inesperadas. Mitchell (2009) resume diferentes formas alternativas de definir y medir la complejidad, desde la cantidad de información necesaria para describir el sistema, o para crearlo, hasta su dimensión fractal. Ninguna de ellas parece sin embargo de fácil aplicación a los organismos, ni siquiera si reduciéndolos a su codificación genética.

La cuestión de la complejidad y del diseño biológico incluye tres temas diferentes: su definición, su medida y sus causas. Estos tres temas, aunque independientes, están interrelacionados. A menudo, propuestas de definición y medida de la complejidad implican un compromiso también con sus causas, como en el caso de Grafen, que identifica el diseńo con incrementos en eficacia causados por la selección.

Para evitar todos estos problemas, proponemos un modelo bi-dimensional forma/función que mueve el enfoque de la complejidad tout court a los cambios en la complejidad de los diseños biológicos. El modelo interpreta los fenómenos evolutivos como cambios en la morfología y/o en las funciones de un organismo (e.g. Mayr 1960, Erwin 2015). Con respecto a la morfología, un cambio evolutivo puede (Müller 2008): (a1) causar cambios únicamente relacionales, (a2) cualitativos o (a3) cuantitativos en un rasgo existente; (b) conllevar un nuevo rasgo; (c) definir un nuevo módulo, o un conjunto de rasgos que configuran una unidad de construcción; (d) requerir un nuevo bauplan, o una nueva configuración de módulos. Las tablas $4{ }^{\mathrm{a}}$ y $4 \mathrm{~b}$ presentan algunos ejemplos. 
Tab. $4 a$ - Posibles cambios morfológicos en un rasgo existente.

\begin{tabular}{|l|l|}
\hline (a1) & $\begin{array}{l}\text { La pérdida de la simetría en la } \\
\text { posición de las orejas en algunas } \\
\text { especies de búhos permite detectar } \\
\text { la altura de los sonidos del suelo } \\
\text { (Konishi \& Volman 1990, 1994). }\end{array}$ \\
\hline (a3) & $\begin{array}{l}\text { El color de las alas de la Biston } \\
\text { betularia cambia como consecuencia } \\
\text { de las nuevas necesidades de } \\
\text { mimetismo ligadas al cambio en el } \\
\text { entorno (Cook \& Saccheri 2013. } \\
\text { Vant Hoff et al. 2016). }\end{array}$ \\
\hline cambios en un rasgo existente & $\begin{array}{l}\text { Serie de especies de el asmothere } \\
\text { caracterizada por un incremento de } \\
\text { las medidas del cuerno a lo largo de } \\
\text { su evolución (Janis 1982). }\end{array}$ \\
\hline
\end{tabular}

TAB. 4B - Posibles nuevos elementos morfológicos.

(b) Nuevo rasgo


Con respecto a la función, el cambio evolutivo puede: (a) dejarla inmutada, como en el caso de la $B$. betularia. Podemos resumir esta situación con 'hacer lo mismo de la misma forma'; (b) mejorar de forma incremental alguna habilidad ya poseída por el organismo, como en el caso de nuevas rutas metabólicas, es decir 'hacer lo mismo de una forma nueva'; (c) conllevar una función del todo nueva, como en el caso de la termorregulación ligada a las plumas, es decir 'hacer algo nuevo'. La tab. 5 resume estos conceptos.

TAB. 5. Posibles cambios funcionales en un fenómeno evolutivo

\begin{tabular}{|c|c|c|c|}
\hline $\begin{array}{c}\text { Función después del } \\
\text { fenómeno evolutivo }\end{array}$ & Tipo de cambio & \multicolumn{2}{|c|}{ Ejemplo } \\
\hline La misma & $\begin{array}{c}\text { Hacer lo mismo } \\
\text { de la misma forma }\end{array}$ & Mimetismo & B. betularia \\
\hline Mejorada & $\begin{array}{c}\text { Hacer lo mismo } \\
\text { de una nueva } \\
\text { forma }\end{array}$ & Alimentación & $\begin{array}{c}\text { Pinzones de } \\
\text { Darwin }\end{array}$ \\
\hline Nueva & Hacer algo nuevo & Termorregulación & $\begin{array}{c}\text { Aparición de las } \\
\text { plumas }\end{array}$ \\
\hline
\end{tabular}




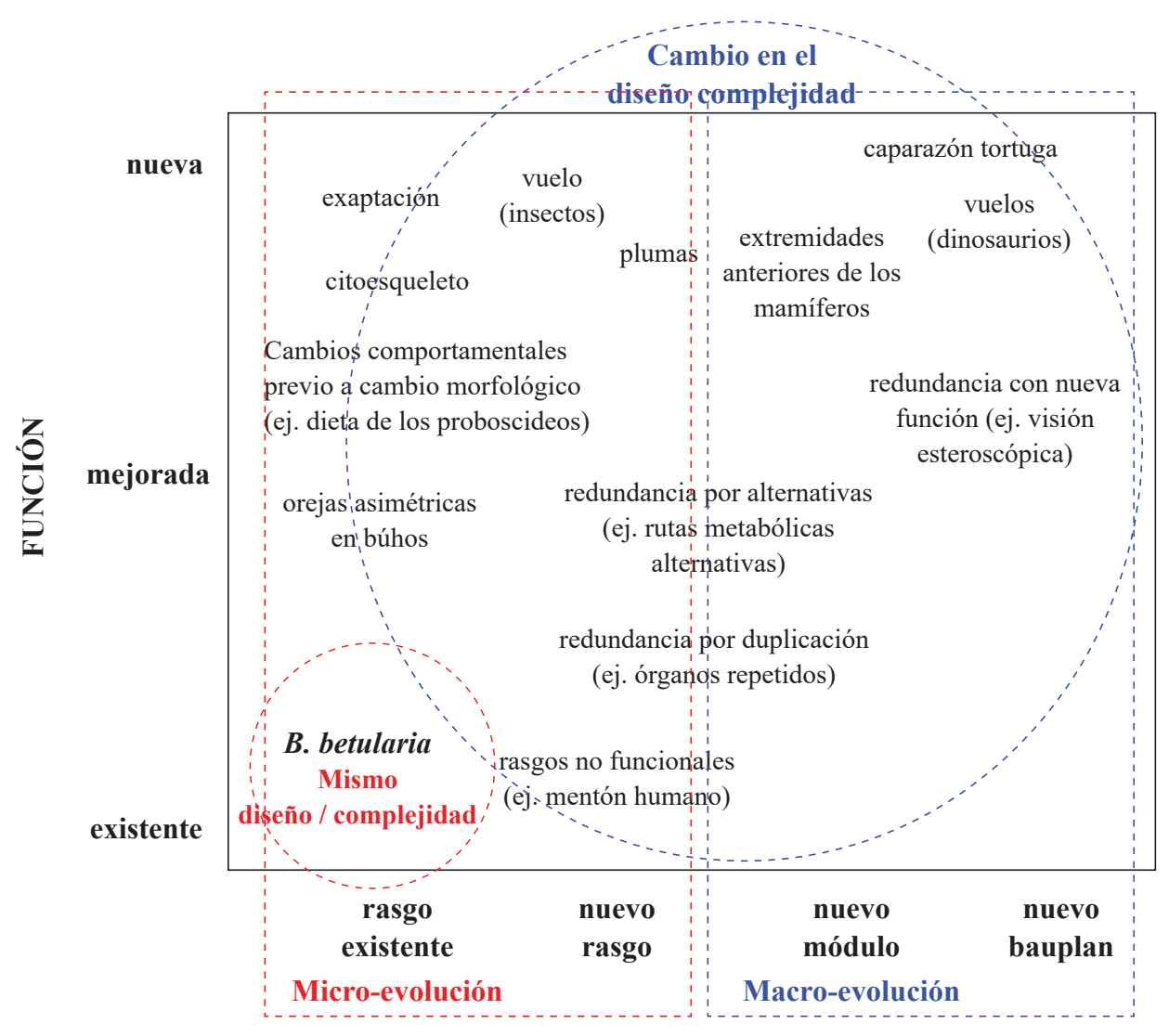

MORFOLOGÍA

Fig. 5 - Espacio bi-dimensional forma-función del diseño biológico complejo

Cualquier cambio evolutivo se puede de esta forma mapear en el espacio forma-función (fig. 5):

- El polimorfismo de la B. betularia no conlleva cambios en forma ni en función: el color de las alas, sea blanco o negro, asegura el mimetismo contra los predadores. Dificilmente podemos afirmar que ha habido un cambio en la complejidad del diseño biológico.

- Las exaptaciones son cambios de función pero no de forma: la nueva función es llevada a cabo por un rasgo existente. Bajo la consideración 
de complejidad como tipos de partes (Mc Shea 1991, 1996), o número de partes (McShea \& Brandon 2010), una exaptación no representa un incremento en complejidad. Bajo nuestro modelo, por otro lado, sí representa un cambio de diseño. La evolución del citoesqueleto es un ejemplo (Wickstead \& Gull 2011).

- La evolución de las extremidades anteriores en los mamíferos a partir de un ancestro tetrápodos común representa un cambio basado en nuevas funciones y nuevos módulos. Los elementos salientes de este fenómeno evolutivo han sido (Brandon 2005: 53):

- Los mamíferos mas antiguos eran tetrápodos con miembros anteriores y posteriores muy poco diferenciados (funcionalmente y morfológicamente);

- Los miembros anteriores han evolucionado en aletas (ballenas), alas (murciélagos) y manos (humanos), aptos para las nuevas funciones de nadar, volar y manipular objetos.

- El miembro anterior ha evolucionado como un nuevo módulo, sin cambios en el bauplan general, puesto que, por ejemplo, los sistemas circulatorios de ballenas, murciélagos y humanos son similares, y que además los miembros anteriores han evolucionado independientemente de los posteriores (los murciélagos no tienen dos pares de alas, ni los humanos dos pares de brazos).

- La redundancia funcional obtenida por duplicación de órganos (por ejemplo, dos riñones) representa un cambio en morfología (básicamente un nuevo módulo), sin nuevas funciones.

- La redundancia funcional obtenida gracia a formas alternativas de llevar a cabo la misma función (por ejemplo, rutas metabólicas alternativas) conlleva un cambio morfológico (un nuevo rasgo).

- La visión estereoscópica es un caso de redundancia por duplicación que, al mismo tiempo, mejora la función de la visión y modifica la morfología a través de un nuevo bauplan. Lo mismo ocurre con el oído basado en dos orejas simétricas, que permite identificar la dirección de un sonido y mejora el equilibrio. 
- La pérdida de simetría en altura de las orejas de algunos búhos permite identificar la altura, y no solo la dirección, de los sonidos: ruidos que se originan por encima o por debajo del nivel de los ojos suenan más altos en el oído derecho o izquierdo respectivamente. La asimetría ha evolucionado en tres formas diferentes en especies diferentes (Konishi \& Volman 1990, 1994; Payne 1971), lo que sugiere una aparición independiente ligada a una ventaja adaptativa: la capacidad de localizar presas en la oscuridad. Se trata claramente de una función mejorada, pero no del todo nueva, puesto que la habilidad de identificar la dirección de un sonido gracias a la redundancia ya existía; y se trata del mismo rasgo, aunque relacionalmente modificado.

- La función del vuelo ha evolucionado de forma diferente en insectos y dinosaurios:

- En los insectos, las alas aparecieron como mecanismos de termorregulación, y la transición hacia una función aerodinámica conllevó únicamente cambios isométricos en las dimensiones del cuerpo, mientras que cambios en la forma del cuerpo no fueron un pre-requisito para este cambio funcional (Kingsolver and Koehl 1985: 488). Una función del todo nueva apareció sin relevantes cambios morfológicos;

- En los dinosaurios, la función del vuelo se debe a la aparición de las plumas como mecanismo de termorregulación, y su posterior exaptación para cumplir una papel aerodinámico. El fenómeno evolutivo fue más complejo que en el caso de los insectos, y conllevó varios pasos intermedios con profundas modificaciones de todo el bauplan (Prim 1999).

- El caparazón de la tortuga conlleva un nuevo bauplan y una nueva función (Burke 1989).

- Los rasgos no-funcionales tienen también su lugar en la matriz 9 por ejemplo, el mentón en los humanos). 
Este sencillo modelo presenta múltiples ventajas: renuncia a la búsqueda de una definición absoluta de complejidad biológica; proporciona una forma de trazar los cambios en diseños complejos separando la evolución de la forma y de la función, que es la única manera de entender la relación entre complejidad y cualquier funcionalidad (McShea \& Brandon 2010); y, sobre todo, se mantiene agnóstica con respecto a las causas del cambio, permitiendo así tomar en cuenta cualquier fuente de variación (la selección, otras fuerzas o una mezcla de ellas) y de clasificar los fenómenos evolutivos sin comprometerse a priori con una explicación evolutiva en concreto.

\section{Eficacia reproductiva y robustez fenotípica}

En el apartado anterior hemos ilustrado y criticado las tres premisas del modelo de Grafen, evidenciando como se basen en el uso de la eficacia como única variable en las formalizaciones adptacionistas. En particular, hemos visto cómo:

A. Medir los cambios evolutivos únicamente en términos de eficacia hace que cualquier otra fuerza no-selectiva resulte transparente para el modelo: no podemos detectar los cambios neutros a corto plazo con respecto a la eficacia, y que sin embargo podrían incrementarla a medio y largo plazo, cuando cambien las condiciones ecológicas.

B. Interpretar la eficacia a la vez como causa y efecto de un rasgo vacía la teoría de la selección natural de poder explicativo.

C. Definir el diseño biológico en términos de maximización de la eficacia presupone que los rasgos y sus funciones no cambien sustancialmente, y no puede dar razón de los cambios evolutivos que comporten novedades más allá de la reconfiguración de acervos genético existente.

Como hemos subrayado, estas premisas son coherentes con el enfoque adaptacionista, del cual el modelo de Grafen es una formalización brillante y exitosa. Creemos, sin embargo, que una explicación exhaustiva de la evolución debe incluir la acción de fuerzas no-adaptativas, que, a causas de las citadas limitaciones, no tienen ni pueden tener un lugar en el modelo de Grafen. Para superar este 'impasse', es necesario integrar el concepto de 'eficacia como efecto' con otra 
medida del impacto de fenómenos evolutivos no-selectivos y, al mismo tiempo, abandonar el concepto de 'eficacia como causa' y sustituirlo por otra medida del éxito potencial de un rasgo, que refleje su capacidad ex ante de contribuir a la sobrevivencia en un entorno y a la vez sea independiente de su éxito reproductivo. En este apartado, proponemos identificar esta variable en la robustez.

La robustez biológica mide la capacidad del organismo para sobrevivir a cambios más o menos radicales del entorno, gracias a la disposición para desarrollar nuevos rasgos y funciones. Podemos definirla en modo informal como el conjunto de las habilidades que el organismo posee, aunque no utilice. Parece complicado llegar a una definición más formal. El concepto de canalización de Waddington (1957) se puede interpretar como una primera aproximación a la idea de robustez. Waddington nota como organismos sometidos a un inusual estrés ambiental durante el desarrollo muestran una mayor variación fenotípica, y que estas variaciones, si el estrés se mantiene generación tras generación, tiende a fijarse y a aparecer en las generaciones siguientes aunque el estrés se elimina. Explica este fenómeno con la emergencia de mecanismos que ponen a salvo el organismos de turbulencias repetidas, y que permiten la aparición del mismo fenotipo frente de genotipos diferentes. Moczek (2008) recurre a una idea parecida para explicar la aparición de novedades fenotípicas: la canalización de los procesos de desarrollo, es decir, la capacidad de mantener el mismo fenotipo frente a cambios en los inputs genéticos o ambientales, permite la acumulación de variación genética críptica (sin efectos fenotípicos) que, superado cierto umbral, lleva a novedades fenotípicas. Kitano define la robustez "una propiedad que permite que un sistema mantenga sus funciones a pesar de perturbaciones externas e internas" (2004: 826, TdA). Un sistema robusto no se mantiene fijo, si no que modifica su estructura o forma de operar de manera que garantiza la continuidad de su función: empujado lejos del equilibrio por una perturbación, vuelve al equilibrio inicial (que Kitano define 'atractor'), o a otro equilibrio, en lugar de disolverse (fig. 6). Truchetet y Pradeu siguen esta definición al afirmar que la robustez coincide con "el mantenimiento de funciones específicas de un sistema dado frente a perturbaciones internas y externas" (2018: 45, TdA). Pigliucci (2008a) mueve el enfoque de las funciones actuales a las nuevas, y ve la robustez como una pieza fundamental de la 'evolvabilidad' en sentido estricto, o la propensión de desarrollar nuevos rasgos y funciones, que incluye también características como la modularidad y la mapa genotipo-fenotipo. Wagner (2011, 2015) unifica de alguna forma las visiones de Pigliucci y de Kitano: considera la robustez a la vez la persistencia de un sistema biológico frente al cambio y su habilidad para desarrollar nuevas funciones. 


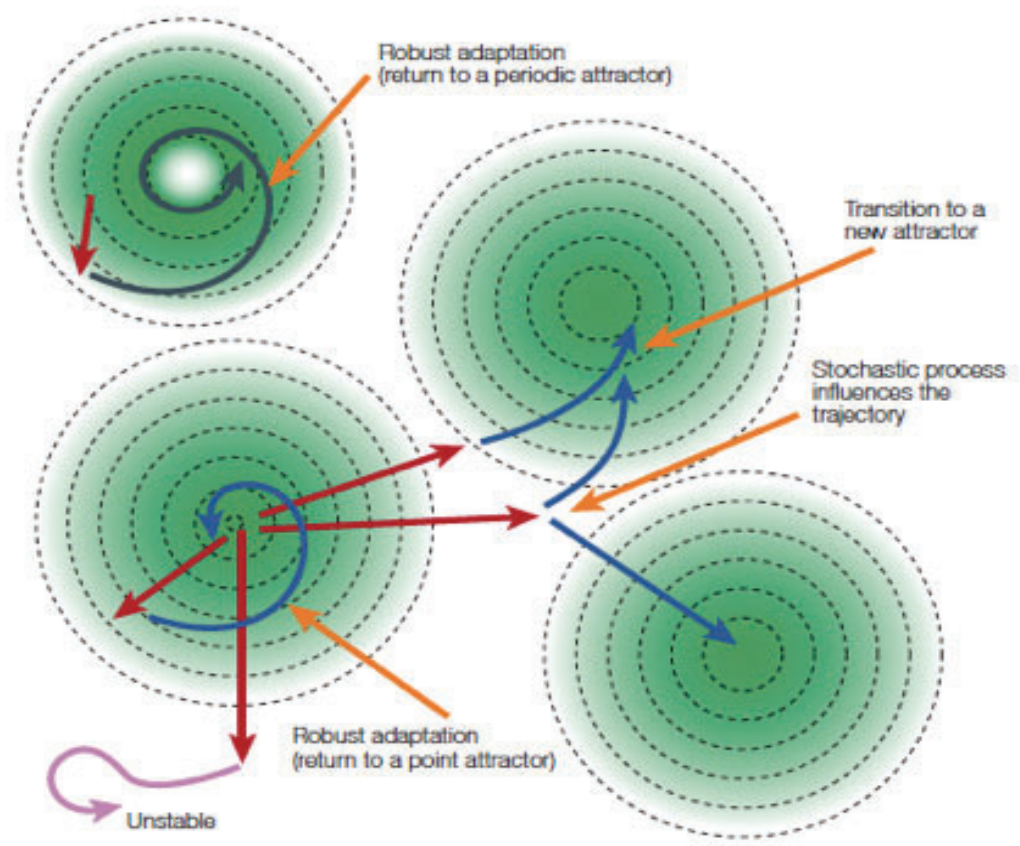

Robust reactions of the system: to stay or to change. The state of a system can be shown as a point in the state spsce. In this case, the state space is simplfied into two dimensions. Perturbations forcefully move the point representing the systern's state. The state of the systern might return to its original attractor by adapting to perturbations, often using a negative feedback loop. Bacterial chemotaxis is an example. There are basins of attractions in the state space within which the state of the systern moves back to that attractor. If the boundary is exceoded, the system might move into an unstabie region or move to other attractors. Positive feedback can either move the systern's state away from the current attractor, or push the system towards a new state. The cell cycle involves a combination of positive and negative feedbacks that faciltate transition between two attractors (G1 and S/G2/M) creating a bistable system. Often, stochastic processes affect transition between attractors, as seen in $\lambda$-phage fate decision, but maintenanoe of a new/ state has to be robust against minor perturbations.

Fig. 6. Los atractores en el espacio de estados (figura y texto de Kitano 2004). El estado de un sistema se puede representar como un punto en el espacio de estados (en este ejemplo, de dos dimensiones). Las perturbaciones mueven el punto que representa el estado del sistema. El estado del sistema puede volver a la situación inicial, por ejemplo gracias a mecanismos de retroalimentación negativa: la quimiotaxis bacteriana es un ejemplo. Existen áreas del espacio de estados dentro de las cuales el sistema es capaz de volver al estado inicial. Si las fronteras de estas áreas se cruzan, el sistema entra en un área de instabilidad o bien en una nueva área de equilibrio. La retoralimentación positiva puede alejar el sistema del atractor inicial o moverlo hacia uno nuevo. El ciclo celular incluye una combinación de retroalimentación positiva y negativa que facilita la transición entre atractores $(\mathrm{G} 1$ y S/G2/M), creando un sistema bi-estable. 
Es posible medir la robustez de un sistema biológico independientemente de su éxito reproductivo, luego sin recurrir a consideraciones ex post, ya que la robustez está ligada a características objetivas de la arquitectura de un organismo, entre las cuales:

- Retroalimentación positiva y negativa (Kitano 2004, Kauffman 1969, Khammash 2016). La retoralimentación es un mecanismo en bucle a través del cual un sistema responde a las perturbaciones o bien magnificándolas (retroalimentación positiva) o bien contrastándolas (retroalimentación negativa). En los sistemas biológicos, la retroalimentación típicamente conlleva algún señal que acelera o inhibe un proceso. En la quimiotaxis, por ejemplo, el movimiento de la bacteria es guiado por estímulos químicos, que empujan el organismo hacia una fuente de energía (por ej. Glucosa) o lo alejan de una sustancia venenosa (por ej. Fenol).

- Redundancia de algún elemento (Kitano 2004, Whitacre 2012). Si varias copias de un elemento de un sistema llevan a cabo la misma función (por ej. Órganos duplicados), el sistema está protegido contra el fallo de una de las copias.

- Diversidad de las funcionalidades del sistema (Kitano 2004, Whitacre 2012). Una función perdida por el fallo de algún elemento del sistema puede ser recuperada llevándola a cabo de una forma diferente (por ej. Glicolisis y fosforización oxidativa son rutas metabólicas alternativas).

- Modularidad (Kitano 2004, Bich 2018, Pigliucci 2008a). Wagner (2015) subraya la existencia de muchos puntos en común entre la tecnología y la naturaleza: entre ellos, la existencia de unos pocos estándares (por ej. La codificación universal del ADN) que permiten reciclar y combinar entre ellos módulos ya existentes. La mayoría de los sistemas biológicos conciste de módulos morfológicos, funcionales, de desarrollo y temporales, de forma que perturbaciones y daños que afecten a un módulo no se expanden a otros (Wagner et al. 2005, Callebaut \& Rasskin-Gutman 2005).

- Desacoplamiento entre los niveles del sistema (Kitano 2004, Rutherford 2000, Masel and Siegal 2009). El sistema se puede defender de las perturbaciones aislando las que le afectan a diferentes niveles, 
como ocurre en el sistema genético y regulatorio (fenómeno conocido como buffering, literalmente 'amortiguamiento'). La proteína Hsp90, por ejemplo, juega este papel asegurando que el estrés ambiental y las mutaciones no afectan al desarrollo (Jablonka and Lamb 2005).

- Cooperación entre elementos (Masel \& Siegal 2009). Un proceso compuesto por varias fases, cada una de las cuales es robusta dentro de una determinada gama de errores, ve su robustez multiplicada, ya que es muy poco probable que todas las fases contengan errores.

- Respuesta on-off en lugar de respuestas lineares. Si un elemento del sistema no responde a variaciones externas hasta que éstas alcancen un umbral mínimo, el sistema está protegido contra la mayoría de perturbaciones.

Contrariamente a la eficacia, estas características pueden surgir gracias a cualquiera de los mecanismos no selectivos citados anteriormente y se pueden medir ex ante; sin embargo, su presencia no garantiza que el organismo tendrá mayor éxito reproductivo, lo que únicamente se podrá determinar ex post una vez superada la fase de selección. El problema de cómo medir la robustez y de cómo incluirla en una formalización de la evolución que, además de la selección, incluya fuerzas y mecanismos no-selectivos, es una tarea abierta que trasciende el alcance de este artículo. Sin embargo, ya hay propuestas en este sentido en el campo de la biología (Kitano 2004, 2007),

El uso de una segunda variable en los modelos formales permite ensanchar su capacidad explicativa. Como ejemplo, notemos la similitud de la figura con un paisaje adaptativo (Wright 1932) observado desde arriba (fig. 7), donde el estado del sistema se corresponde con la eficacia y los atractores con los picos de eficacia. La población puede alejarse del equilibrio (pico de eficacia) por un fenómeno de deriva genética, o por cambio en el entorno: en ambos casos, o bien se disolerá o bien volverá al mismo o a un nuevo pico. Es evidente la similitud con los movimientos del sistema en el espacio de estados de Kitano, y si este espacio se basara únicamente en la eficacia, su contenido informativo no sería mayor que él del paisaje adaptativo: se trataría simplemente de una diferente representación gráfica. Lo que el concepto de robustez añade al paisaje adaptativo es la explicación ex ante de porqué un pico es más alto que otro. El paisaje se limita a registrar gráficamente la eficacia reproductiva medida ex post de diferentes fenotipos (o mix genéticos): no se puede construir si los fenotipos no han pasado por una fase de selección. El 
paisaje no explica porqué los organismos representados por los puntos a y b, aún poseyendo la misma eficacia, tienen potenciales evolutivos diferentes: la población $\mathrm{b}$ tenderá a un pico de eficacia mayor que la población a. El análisis de la robustez del fenotipo b, sin embargo, puede proporcionar esta información.

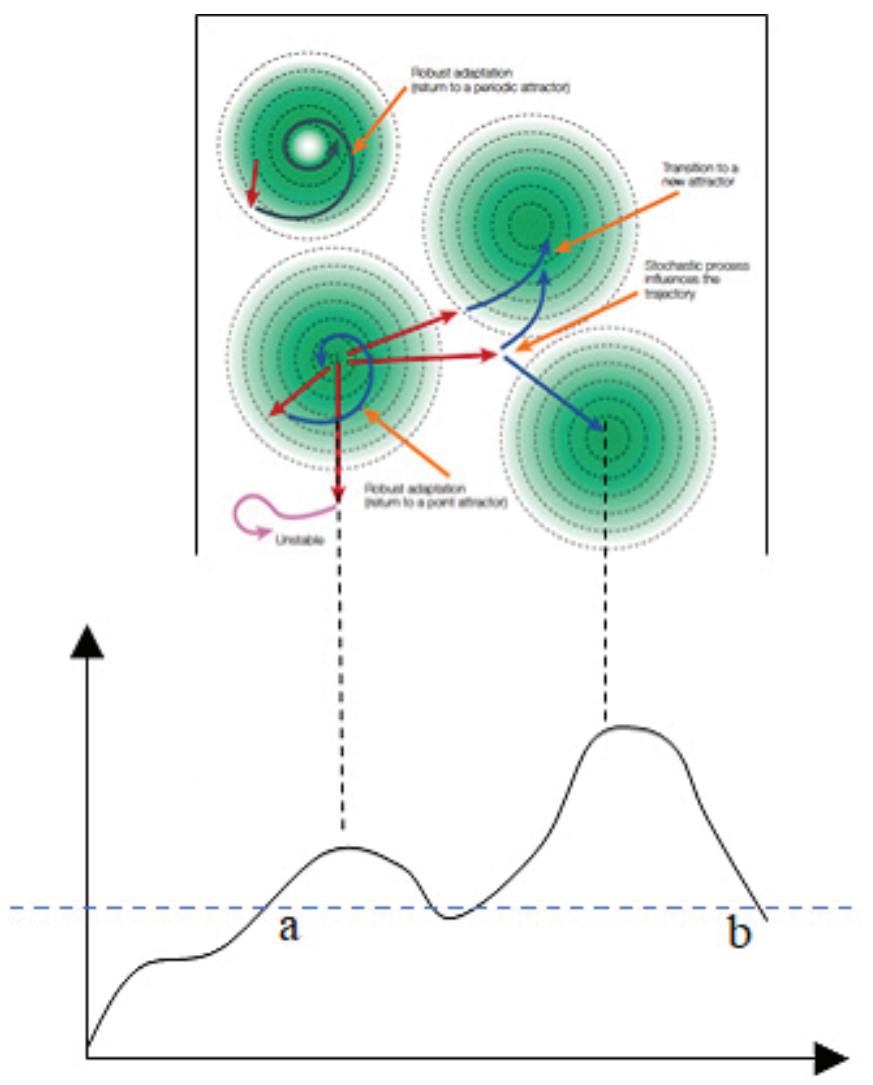

Fig. 7. Espacio de estados, robustez y paisaje adaptativo. El paisaje adaptativo se puede interpretar como una sección mono-dimensional de un espacio de estados. Las zonas de picos de eficacia, donde las poblaciones tienden a situarse y a volver en caso de perturbaciones, equivalen a las áreas de robustez de la propuesta de Kitano. 


\section{Conclusiones}

El Proyecto del Darwinismo Formal de Grafen se propone la unificación de los modelos de genética de poblaciones con los argumentos adaptacionistas para dotar de una base matemática el argumento de Darwin y demostrar que la selección natural es causa necesaria y suficiente para explicar el surgimiento del diseño complejo en los organismos.

El modelo representa una exitosa formalización del paradigma adaptacionista: sin embrago, creemos que le evolución es más que simple adaptación. En este sentido, las criticas al adaptacionismo se aplican también al modelo de Grafen: en este artículo, hemos avanzado tres de ellas. En primer lugar, se ha mostrado que Grafen no considera que otros mecanismos, además de la selección, pueden contribuir al diseño. De acuerdo con su modelo, la selección puede explicar todos los rasgos actuales del organismo, así como generar nuevos rasgos. Sin embargo, en las últimas décadas se han propuestos otras fuerzas y mecanismos como motor de la evolución, que no se pueden obviar con la excusa de su nula contribución a la eficacia, ya que ésta es, por definición, una medida de selección. En segundo lugar, el modelo de Grafen aplica el concepto de eficacia de genética de poblaciones y cambia radicalmente, aunque sutilmente, su alcance, transformándolo de predictivo en explicativo: lo que transforma la teoría de la selección en un truismo.

Finalmente, Grafen no proporciona una definición formal de diseño, y se limita a identificarlo como el resultado de un proceso de optimización de la eficacia. En conclusión, el modelo de Grafen representa una genuina contribución a la solución de los problemas que identifica; sin embargo, su aplicabilidad se limita a cierto cambios evolutivos simples, y esto deja sin analizar una gran parte de los hechos evolutivos ligados al diseño.

Para superar estas limitaciones, proponemos sustituir como explicans de los rasgos el concepto de eficacia por él de robustez. La robustez fenotípica permite medir las contribuciones de cambios evolutivos antes de la fase de selección, además del efecto de todas aquellas fuerzas que Grafen (y el adaptacionismo en general) ignora. El uso de la robustez permite además evitar el truismo, ya que proporciona un criterio independiente del éxito de la selección para identificar el 'más apto'. 
Una vez introducida esta segunda variable al estudio de los fenómenos, se abren varias líneas de investigación, entre las cuales cabría destacar: la medición de la robustez fenotípica; la identificación de cómo las distintas fuerzas no selectivas pueden impactar la robustez de un fenotipo; el estudio del efecto combinado de la selección y de las fuerzas no selectiva en fenómenos evolutivos complejos, etc.. El resultado del impacto de estas investigaciones se podrá interpretar gracias al espacio bi-dimensional que se ha propuesto en este trabajo, en donde se pueden mapear y trazar los cambios evolutivos de una población en términos de cambios en eficacia y robustez.

\section{Bibliografía}

Adami, C., Ofria, C., Collier, T. C. (2000). Evolution of biological complexity. PNAS, 97(9): 4463-4468

Alberch, P. (1991). From genes to phenotypes: dynamical systems and evolvability. Genetica 84: 5-11

BicH, L. (2018). Robustness and autonomy in biological systems: how regulatory mechanisms enable functional integration, complexity and minimal cognition through the action of second-order control constraints. In M. Bertolaso, S. Caianiello \& E. Serrelli (Eds.), Biological Robustness. Emerging Perspectives from within the Life Sciences:123-147. New York: Springer.

BirCh, J. (2014). Has Grafen formalized Darwin?, Biol Philos, 29: 175-180

Carlson, J. M., Doyle, J. (1999). Highly Optimized Tolerance: A Mechanism for Power Laws in Designed Systems. Phys. Rev.E 60:1412

Charnov, E. L. (1976). Optimal Foraging, the Marginal Value Theorem, Theoretical Population Biology, 9 (2) 129-136

Darwin, C. R. (1872, $6^{\text {th }}$ Edition). On the Origin of Species. John Murray, London.

Dupré, J. (2006). El legado de Darwin. Qué significa hoy la evolución. Katz

Eldredge, N. \& Gould, S.J. (1972). Punctuated equilibria: an alternative to phyletic gradualism, in Models in paleobiology, Shopf, TJM Freeman, Cooper / Co.

Erwin, D. H. (2015). Novelties and Innovations in the History of Life. Current Biology 25, R930-R940 
Ewens, W. J. (2014) Grafen, the Price equations, fitness maximization, optimization and the fundamental theorem od natural selection, Biol Philos, 29: 197-205

Fisher, R. A. (1930). Genetical theory of natural selection. Oxford Clarendon Press.

Gardner, A. (2008). The Price equation, Current Biology, 18 (5): 198-202

- ,(2009). Adaptation as organism design. Biology Letters, 5(6): 861.

- ,(2014a). Life, the universe and everything, Biol Philos, 29: 207-215

- ,(2014b). Adaptation of individuals and groups, en Bouchard, F, Huneman, P. (eds.), From Groups to Individuals, The MIT Press: 99-116

Gould S.J., Lewontin S.J. (1979). The spandrels of San Marco and the Panglossian paradigm: a critique of the adaptationist program, Proc. R. Soc. Lon., B 205: 581598

Gould, J.S., VRBA, E. S. (1982). Exaptation - A Missing Term in the Science of Form, Paleobiology, 8 (1): 4-15

Grafen, A., (1999), Formal Darwinism, the individual-as-maximizing-agent and betedging, Proc. R. Soc. Lond. B, 266: 799-803

- ,2000). Development of the Price equation and natural selection under uncertainty, Proc. R. Soc. Lond. B , 267,:1223-1227

- ,2002). A first formal link between the Price equation and an optimization program, J. theor. Biol. 217: 75-91

- ,(2006a). Optimization of inclusive fitness, J. theor. Biol. 238: 541-563

- ,(2006b). A theory of Fisher reproductive value. J. Math. Biol. 53: 15-60

- ,(2007). The Formal Darwinism project: a mid-term report, J. Evol. Biol., 20 (4): 1243-1254

- ,(2008). The simplest formal argument for fitness optimization, Journal of Genetics, 87 (4): 421-433

- ,(2009). Formalizing Darwinism and inclusive fitness theory, Phil. Trans. R. Soc. B $364,3135-3141$

- ,(2014a). The formal Darwinism project in outline, Biol Philos, 29: 155-174

- ,(2014b). The formal Darwinism project in outline: response to commentaries, Biol Philos, 29: 281-292 
Hamilton (1964). The Genetical Evolution of Social Behaviour, J,. Theoret. Biol., 7: $1-52$

Houle, D. (1992). Comparing evolvability and variability of quantitative traits, Genetics 130: 195-204

Huneman, P. (2014). Formal Darwinism as a tool for understanding the status of organism in evolutionary biology, Biol Philos, 29: 271-279

Jablonka, E., Lamb, M. J. (2005). Evolution in Four Dimensions. Genetic, Epigenetic, Behavioral, and Symbolic Variation in the History of Life. The MIT Press.

Jablonka, E., Lamb, M. J., Avital, E. (1998). Lamarckian' mechanisms in darwinian evolution. Trends in Ecology \& Evolution, Volume 13(5):206-210

Jounson, N. (2010). Simply Complexity: a Clear Guide To Complexity Theory. Oneworld Publications

Kauffman, S. A. (1969). Metabolic stability and epigenesis in randomlyproduced genetic nets. J. Theor. Biol.22:437-467

- ,(1993). The Origins of Order. Self-Organization and Selection in Evolution.. Oxford University Press.

- ,(2000). Investigations. Oxford University Press.

Khammash, M. (2016). An engineering viewpoint on biological robustness. BMC Biology.

Kingsolver, J., Koehl, M. (1985), Aerodynamics, Thermoregulation, and the Evolution of Insect Wings -Differential Scaling and Evolutionary Change. Evolution, 39:488-504

Kitano, H. (2004). Biological robustness. Nature Reviews Genetics, 5(11): 826-837.

Kitano, H. (2007). Towards a theory of biological robustness. Molecular Systems Biology, 3(1), 137-n/a.

Konishi, M., Volman, S. F. (1990). Comparative Physiology of Sound Localization in Four Species of Owls, Brain Behavior and Evolution, 36:196-215

- ,(1994). Adaptations for bi-coordinate soundlocalization in owls. In: Schildberger, K. And Elsner, N. (Eds.), Neural Basis of Behavioral Adaptations. Progress in Zoology;39:1-11.

Koonin, E. V., Wolf, Y. I (2009). Is evolution Darwinian or/and Lamarckian? Biology Direct, $4: 42$ 
Lehmann, L., Rousset F. (2014). Fitness, inclusive fitness, and optimization, Biol Philos, 29: 181-195

Luque, V. J. (2017) One equation to rule them all: a philosophical analysis of the Price equation. Biology and Philosophy 32(1): 97-125.

LyNCH, M. (2007). The frailty of adaptive hypothesis for the origins of organismal complexity. PNAS, 104 (1):8597-8604

Masel, J., \& Siegal, M. L. (2009). Robustness: Mechanisms and consequences. Trends in Genetics, 25(9): 395-403.

Maturana, H., \& Varela, F. J. (1980). Autopoiesis and cognition: The realization of the living. Dordrecht: D. Reidel.

Mayr, E., (1960). The emergence of Novelty. In Tax, S. (ed.), The Evolution of Life, , Univ. of Chicago Press: 349-380.

McShea, D.W. (1991). Complexity and evolution: What Everybody Knows. Biol. Philos.6: 303-324

- ,(1996). Perspective: Metazoan Complexity and Evolution: Is there aTrend?. Evolution, Vol. 50, No. 2: 477-492.

McShea, D.W., Brandon, R. (2010). Biology's First Law: the tendency for diversity and complexity to increase in evolutionary systems. The University of Chicago Press.

Mills, S., Beatty, J. (1979), The Propensity Interpretation of Fitness, Philosophy of Science, 46: 263-286

Millstein, R. L. (2006). Natural selection as a population-level causal process. British Journal for the Philosophy of Science, 57(4):627-653.

Mitchell, M. (2009). Complexity. A Guided Tour. Oxford University Press.

MoczeK, A. P. (2008). On the origins of novelty in development and evolution. BioEssays 30: $432-477$

Mossio, M., Bich, L., \& Moreno, A. (2013). Emergence, closure and inter-level causation in biological systems. Erkenntnis, 78: 153-178.

Okasha, S., Paternotte. C. (2014), Adaptation, fitness and the selection-optimality links, Biol Philos, 29: 225-232

Orzack, S. H. (2014), A commentary on the 'Formal Darwinism Project': there is no grandeur in this view of life, Biol Philos, 29: 259-270 
Payne, Roger S. (1971). Acoustic Location of Prey by Barn Owls (Tyto alba). J Exp Biol.54:535-573

Pigliucci, M. (2008a). Is evolvability evolvable? Nature Reviews Genetics, 9(1): 75-82.

- ,(2008b). Sewell Wright's adaptive landscapes: 1932vs. 1988, Biol Philos, 23: 591-603

Price, G. R. (1972). Fisher's 'fundamental theorem' made clear. Annals of Human Genetics, 36(2): 129.

Rosenberg, A. (1982). On the Propensity Definition of Fitness. Philosophy of Science, Vol. 49, No. 2:268-273

Rosenberg, A., Williams, M. (1986). Fitness as Primitive and Propensity. Philosophy of Science, Vol. 53, No. 3:412-418

Rutherford,S. L. (2000). From genotype to phenotype: buffering mechanisms and the storage of genetic information. Bioessays.22(12):1095-105.

Saborido, C., Moreno, A. J., \& Mossio, M. (2010). La dimensión teleológica del concepto de función biológica desde la perspectiva organizacional. Teorema: Revista Internacional de Filosofía, 29(3): 31-56.

Sarkar, S. (2014), Formal Darwinism, Biol Philos, 29: 249-257

Sober, E. (2009). Philosophy of biology. Westview Press.

Truchetet, M.-E.., Pradeu, T. (2018). Re-thinking our understanding of immunity: Robustness in the tissue reconstruction system. Seminars in Immunology, 36:45-55

Waddington, C. H., (1957). The Strategy of the Genes. George Allen \& Unwin

Wagner, A., (2011), The Origins of Evolutionary Innovations, Oxford University Press

- ,(2015). Arrival of the Fittest, Oneworld Publications

Wagner, G. P., Altenberg, L. (1996). Complex adaptations and the evolution of evolvability, Evolution 50: 967-976

Wagner, G. P., Mezey, J., Calabretta, R. (2005), Natural Selection and the Origin of Modules, in Callebaut, W., Rasskin-Gutman, eds. (2005). Modularity. Understanding the Development and Evolution of Natural Complex Systems. The MIT Press:33-50

Wickstead, B., Gull, K. (2011). The evolution of the cytoskeleton. The Journal of Cell Biology, 194 (4)513-525

WhitaCre J. M. (2012). Biological robustness: paradigms, mechanisms, and systems principles. Frontiers in genetics,3, 67. 
WRIGHT, S. (1932), The roles of mutation, inbreeding, crossbreeding and selection in evolution. In: Proceedings of the sixth international congress of genetics: 356-366

Wright, S. (1982), The shifting balance theory and macroevolution, Ann. Rev. Genet. $16: 1-19$

Recibido: $11 / 11 / 2020$

Aceptado: 27/11/2020

\section{(c) $(1) \Theta \Theta$}

ENDOXA está bajo una licencia de Creative Commons Reconocimiento-NoComercialSinObraDerivada 4.0 Internacional 